\title{
The investigation of NMR spectra of dihydropyridones derived from Curcumin
}

\author{
Bahjat A. Saeed, ${ }^{\mathrm{a}}$ Kawkab Y. Saour, ${ }^{\mathrm{b}}$ and Rita S. Elias ${ }^{\mathrm{c}}$ \\ ${ }^{a}$ Department of Chemistry, College of Education, University of Basrah, Iraq \\ ${ }^{b}$ Department of Pharmaceutical Chemistry, College of Pharmacy, University of Baghdad, Iraq \\ ${ }^{c}$ Department of Pharmaceutical Chemistry, College of Pharmacy, University of Basrah, Iraq \\ E-mail: bas_chem_dep@yahoo.com
}

\begin{abstract}
${ }^{1} \mathrm{H}$ and ${ }^{13} \mathrm{C}$ NMR spectra of dihydropyridones derived from curcumin were discussed and their structures were elucidated accordingly. Both one dimensional, HOMO- and HETERO-COSY spectra were used in this study. Computational calculations using B3LYP/6-311G(d,p) level of theory were undertaken to predict the structural properties of one molecule. The optimized structure was then used to calculate the NMR chemical shifts at the B3LYP/6-311G(d,p) level using the GIAO method. The calculated ${ }^{1} \mathrm{H}$ and ${ }^{13} \mathrm{C}$ chemical shifts were compared with the experimental data. The calculated chemical shifts are in compliance with the experimental findings.
\end{abstract}

Keywords: Curcumin, dihydropyridones, B3LYP/6-311G(d,p), geminal coupling, GIAO method.

\section{Introduction}

Curcumin is the active component of turmeric powder extracted from Curcuma longa L. It has many biological activities ranging from anti-inflamatory to anti-cancer. ${ }^{1-8}$ On the other hand dihydropyridones are important intermediates for the synthesis of natural products, particularly alkaloids. Many approaches to their synthesis have been developed. ${ }^{9-13}$ Two main approaches are used in general, from acyclic precursors ${ }^{14-19}$ and from pyridines. ${ }^{19,20}$

In previous paper, ${ }^{21}$ we reported the microwave assisted synthesis of dihydropyridones from the reaction of curcumin and amines. A structurally related dihydropyridone was synthesized by Sugiyama et. $a l,{ }^{22}$ by the reaction of 6-methyl-1,2-diphenyl-2,3-dihydro-4-pyridone with benzaldehyde which share many spectral characteristics with those of our compounds especially 
${ }^{1} \mathrm{H}$ NMR spectra. This seems very important since the compounds were synthesized through totally different approaches.

The aim of this work is to investigate the NMR spectra of dihydropyridones derived from curcumin and amines under microwave irradiation.

\section{Experimental Section}

The synthesis of the studied compounds was previously reported. ${ }^{21}$ NMR spectra were recorded with a Bruker WM-600 (600 MHz) and Brucker Ultra/Shield $300 \mathrm{MHz}$ spectrometers in $\mathrm{d}_{6^{-}}$ DMSO with tetramethylsilane (TMS) as an internal standard. For theoretical calculations the structure of molecule 1 was fully optimized with B3LYP functional at the $6-311 \mathrm{G}(\mathrm{d}, \mathrm{p})$ basis set using Gaussian 2003 program. ${ }^{23}$ The optimized structure was used to calculate the NMR spectra at the level B3LYP/6-311G(d,p)//B3LYP/6-311G(d,p) using the GIAO method. ${ }^{24}$

\section{Results and Discussion}

The structures of the studied compounds are shown in Scheme 1. The spectral experimental data are gathered in Tables 1 and 2 and some characteristic spectra are shown in Figures 1-4. It is well known that the ${ }^{1} \mathrm{H}$ NMR spectrum of curcumin contains two singlets at 3.83 and $9.69 \mathrm{ppm}$ due to the protons of the two methoxy groups and the protons of the two hydroxyl groups respectively which reflects its symmetric structure. Concerning the studied compounds the spectra are characterized by two singlets each of an integral of three protons at chemical shifts around that of the methoxy groups of curcumin, and another two singlets both with an integral of one proton at chemical shifts around that of the hydroxyl groups of curcumin (Figure 1). 
<smiles>[R]N1C(/C=C/c2ccc(O)c(OC)c2)=CC(=O)CC1c1ccc(O)c(OC)c1</smiles>

where;

$1, \mathrm{R}=-\stackrel{22}{\mathrm{C}} \mathrm{H}_{3}$

$2, \mathrm{R}=-\stackrel{22}{\mathrm{CH}_{2}-\mathrm{CH}_{3}}$

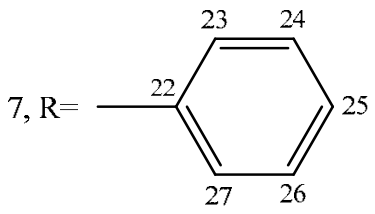

$3, \mathrm{R}=-\underset{22}{22} \mathrm{CH}_{2}-\mathrm{CH}_{2}-\mathrm{CH}_{3}$

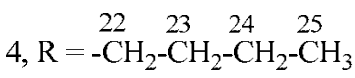

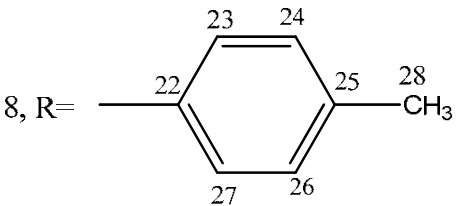

$5, \mathrm{R}=\stackrel{22}{-\mathrm{CH}_{2}-} \stackrel{23}{\mathrm{CH}_{2}-\mathrm{CH}_{2}-\mathrm{CH}_{2}-\mathrm{CH}_{2}-\mathrm{CH}_{3}}$

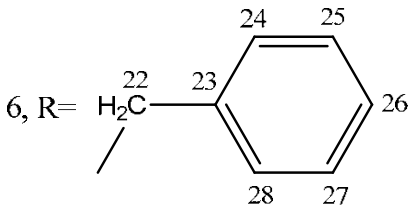

Scheme 1. The molecular structures of the studied compounds.

In compound 3 (Figure 1) these signals appear at 3.74 and $3.82 \mathrm{ppm}$ which are assigned to two methoxy groups at different environments, while the other two signals appear at 8.92 and $9.36 \mathrm{ppm}$ which are assigned to two hydroxy groups at different environments. 


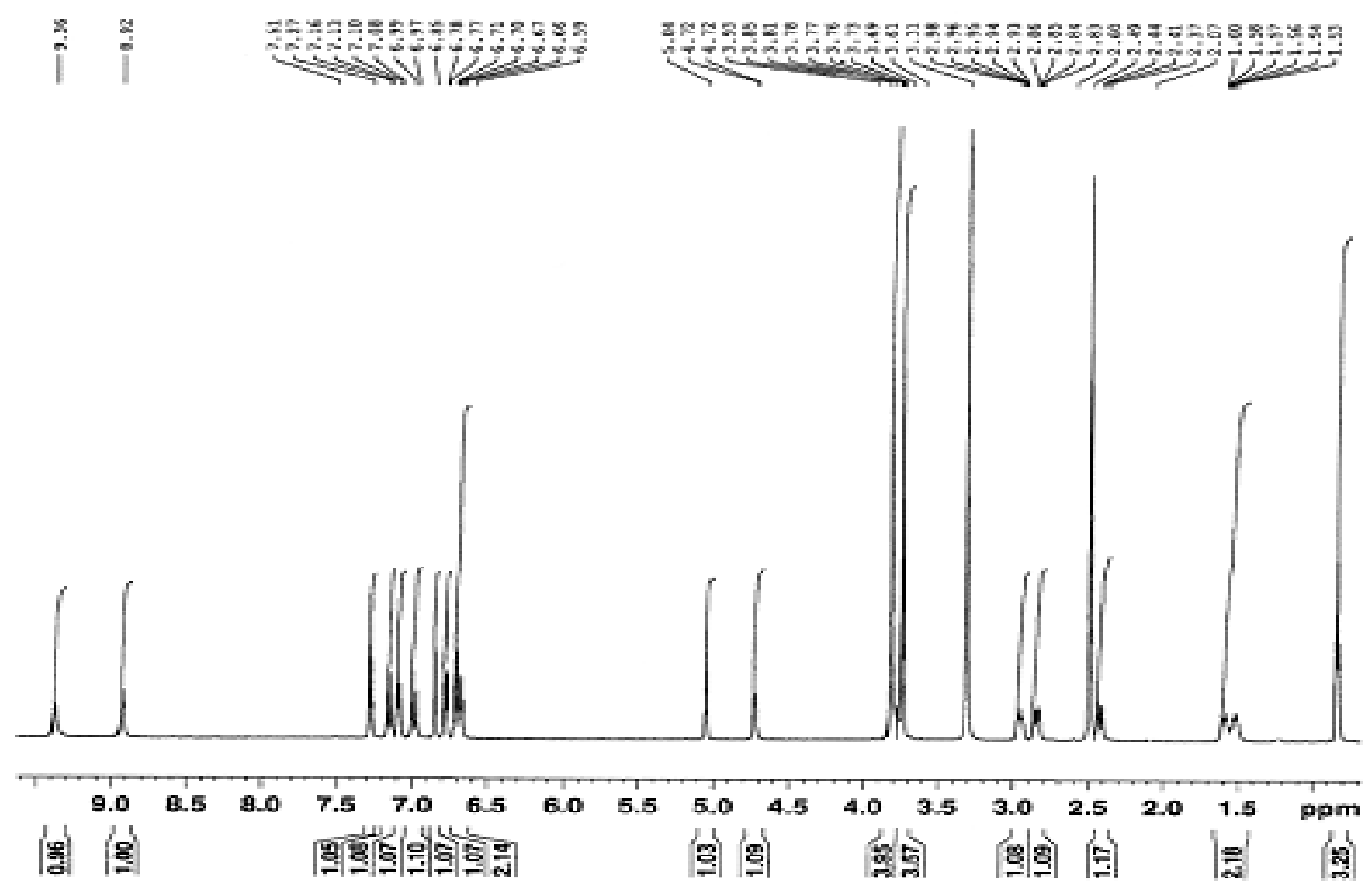

Figure 1. $600 \mathrm{MHz}{ }^{1} \mathrm{H}$ NMR spectrum of compound 3 in $\mathrm{d}_{6}$-DMSO.

The spectra are also characterized by a singlet of one proton integral at the range 5.04-5.42 ppm (Table 1) which is assigned to the vinylic proton. The most important signals which give aid to elucidate the molecular structure of the compounds are those arise within the ranges 2.40-2.63, 2.80-3.08 and 4.66-5.08 ppm each of them has the integral of one proton. In the spectrum of compound 3 they are appear at 2.43, 2.84 and 4.66 respectively (Figure 1). The first two signals are both doublets with coupling constant $16 \mathrm{~Hz}$. In Figure 2 the expanded spectrum of the two doublets in compound $\mathbf{7}$ is shown. The fine structure which appears at the high field side peak may be due to long range coupling to the vinylic proton. The $J$-coupling values suggest that these are belonging to two coupled protons.

Table 1. Chemical shifts $\left(\delta\right.$, ppm) of ${ }^{1} \mathrm{H}$ of the studied compounds.

\begin{tabular}{ccccccccc}
\hline Comp. & 1 & 2 & 3 & 4 & 5 & 6 & 7 & 8 \\
\hline $\mathrm{H} 2$ & $7.29 \mathrm{~s}$ & $7.29 \mathrm{~s}$ & $7.29 \mathrm{~s}$ & $7.28 \mathrm{~s}$ & $7.27 \mathrm{~s}$ & $7.29 \mathrm{~s}$ & $6.96 \mathrm{~s}$ & $6.98 \mathrm{~d}$ \\
& & & & & & & & $J=2 \mathrm{~Hz}$ \\
$\mathrm{H} 5$ & $6.76 \mathrm{~d}$ & $6.76 \mathrm{~d}$ & $6.76 \mathrm{~d}$ & $6.77 \mathrm{~d}$ & $6.77 \mathrm{~d}$ & $6.78 \mathrm{~d}$ & $6.74 \mathrm{~d}$ & $6.74 \mathrm{~d}$ \\
& $J=6 \mathrm{~Hz}$ & $J=6 \mathrm{~Hz}$ & $J=6 \mathrm{~Hz}$ & $J=6 \mathrm{~Hz}$ & $J=6 \mathrm{~Hz}$ & $J=6 \mathrm{~Hz}$ & $J=8 \mathrm{~Hz}$ & $J=8 \mathrm{~Hz}$ \\
$\mathrm{H} 6$ & $7.08 \mathrm{~d}$ & $7.08 \mathrm{~d}$ & $7.08 \mathrm{~d}$ & $7.09 \mathrm{~d}$ & $7.09 \mathrm{~d}$ & $7.08 \mathrm{~d}$ & $6.85 \mathrm{dd}$ & $6.83 \mathrm{dd}$ \\
& $J=6 \mathrm{~Hz}$ & $J=6 \mathrm{~Hz}$ & $J=6 \mathrm{~Hz}$ & $J=6 \mathrm{~Hz}$ & $J=6 \mathrm{~Hz}$ & $J=6 \mathrm{H}$ & $J=2$ and & $J=8$ and \\
& & & & & & & $8 \mathrm{~Hz}$ & $2 \mathrm{~Hz}$ \\
\hline
\end{tabular}


Table 1. Continued

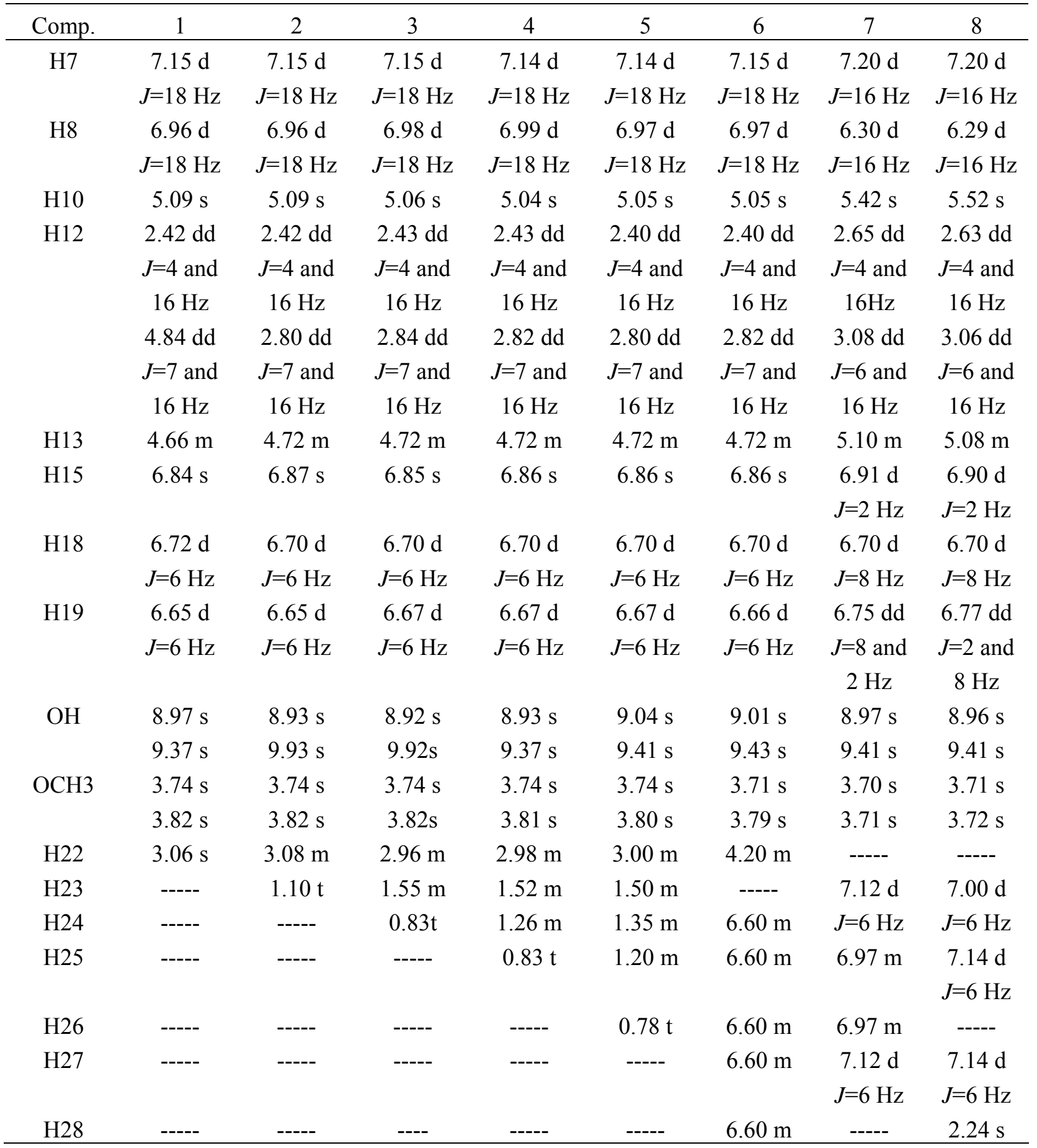

$\mathrm{s}$ singlet $\quad \mathrm{d}$ : doublet $\quad \mathrm{dd}$ : doublet of doublets $\mathrm{t}$ : triplet $\mathrm{m}$ : multiplet 
In addition their positions at the saturated side of the spectrum and their coupling values (16 $\mathrm{Hz}$ ) mean that they are geminal protons. Being further split with different coupling constants suggests that the protons are coupled to a common proton which attains different angles with them. According to the splitting fashion of the peak at $4.66 \mathrm{ppm}$ it could be concluded that this peak is that of the proton of choice (Figure 2).
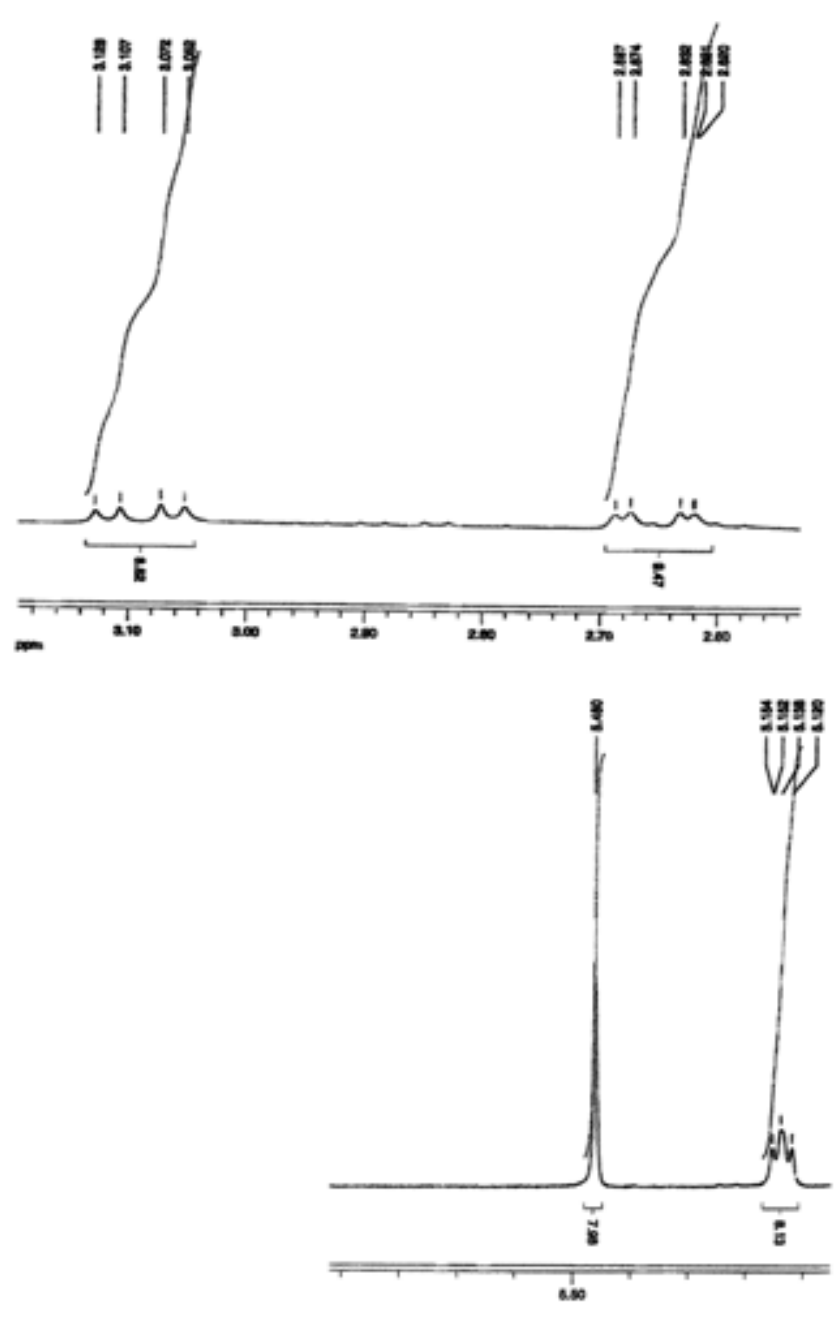

Figure 2. The expanded $300 \mathrm{MHz}{ }^{1} \mathrm{H}$ NMR spectrum of compound 5 within the $2.60-5.50 \mathrm{ppm}$ region.

To go further with the assignment it is fruitful to examine the HETCOR spectrum of compound 3 which is shown in Figure 3. It is clear that the two protons of the peaks at 2.43 and $2.84 \mathrm{ppm}$ are connected to the same carbon atom which has a peak at 42.6 which confirms that they are geminal protons. 


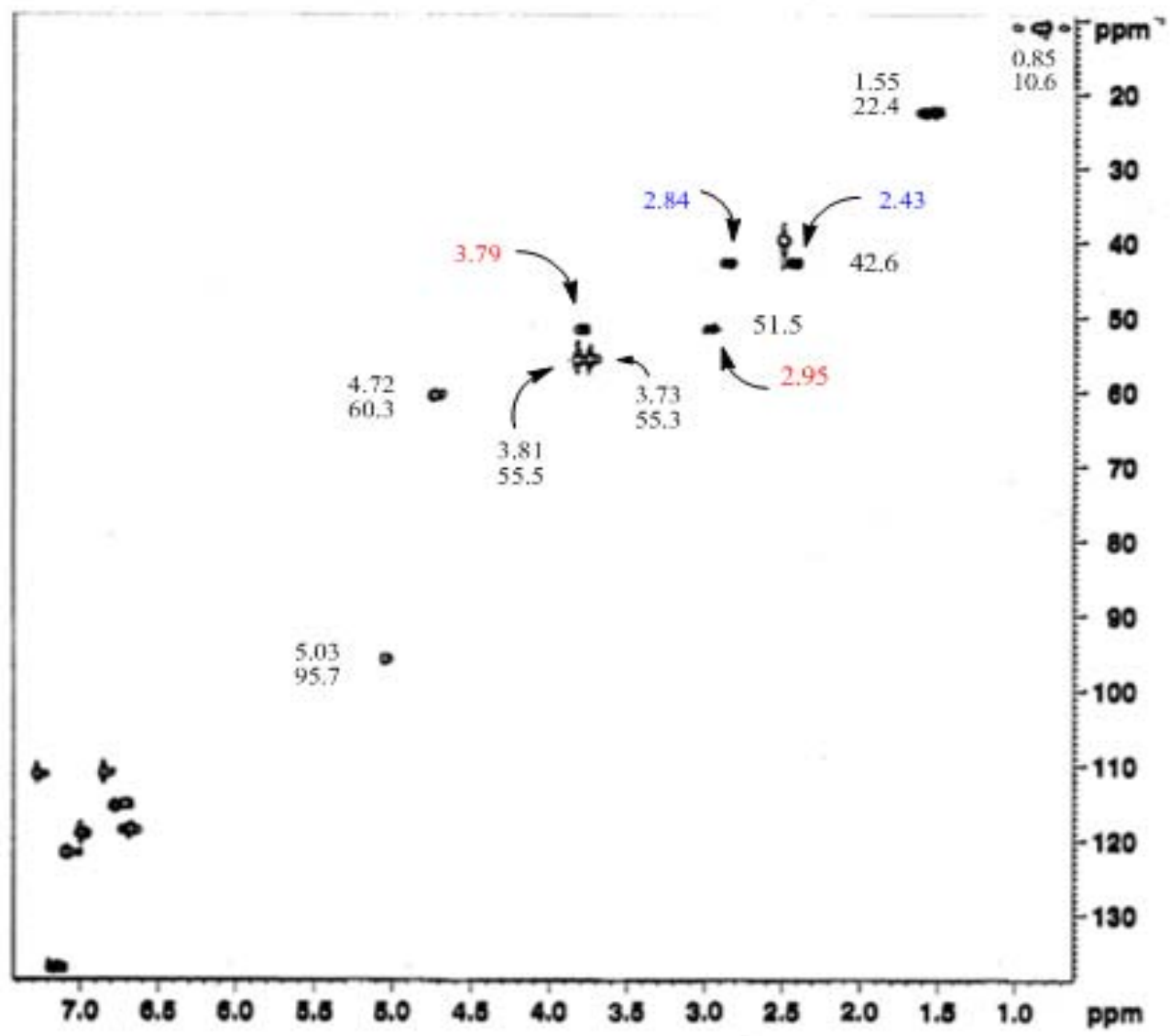

Figure 3. The HETCOR spectrum of compound 3.

Meanwhile, the proton of the peak at $5.03 \mathrm{ppm}$ is connected to the olefin carbon with a peak at $95.7 \mathrm{ppm}$ confirming its vinylic nature.

The important feature in Figure 3 is the two peaks at 2.95 and 3.79 ppm that connected to the carbon of the peak at $51.5 \mathrm{ppm}$ which could be assigned to the $\mathrm{N}-C$ carbon. This suggests that the $\mathrm{N}-\mathrm{CH}_{2}$ - protons of the propyl chain are diastereotopic protons. ${ }^{25}$ Of them the peak at 3.79 ppm which overlaps with the signals of the two methoxy groups protons at 3.73 and $3.81 \mathrm{ppm}$. This overlapping increases the overall integral of these protons to 7 leaving the signal at 2.95 ppm (the N-CH signal) with only one proton integral. The HOMO-COSY spectrum of compound 3 is shown in Figure 4. 


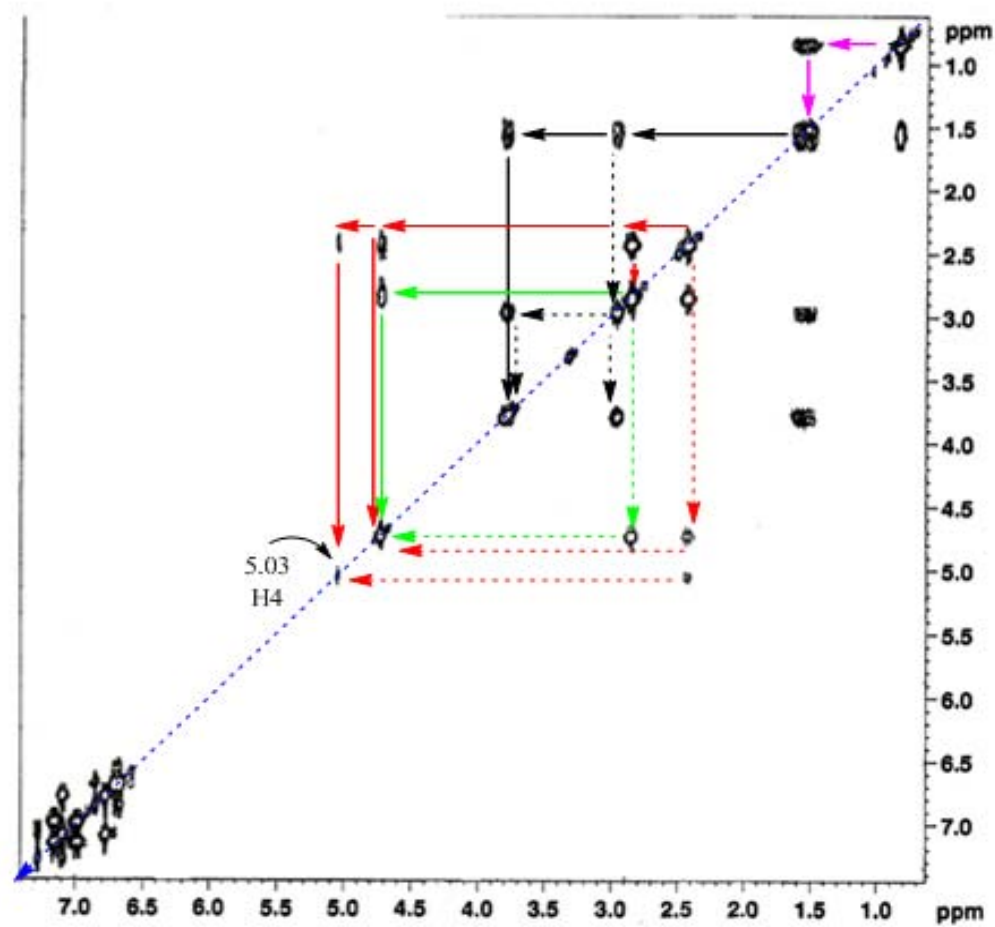

Figure 4. The HOMO-COSY 1H NMR spectrum of compound 3 (600 MHz).

It could be seen that both protons $\mathrm{H} 12$ are coupled to each other at the same time they coupled to the proton H13 since they have cross peaks. There are cross peaks also between the protons H12and $\mathrm{H} 10$ indicating a long range coupling between them. The diastereotopic property of the $\mathrm{N}-\mathrm{CH}_{2}$ protons is confirmed in this figure since there are cross peaks for their peaks at 2.95 and $3.79 \mathrm{ppm}$. The vinylic proton (H10) has a singlet peak at about 5 ppm while the olefinic protons (H7 and $\mathrm{H} 8$ ) have doublet peaks at the ranges 7.14-7.20 and 6.29 and $6.96 \mathrm{ppm}$ respectively. The chemical shifts of the protons $\mathrm{H} 12, \mathrm{H} 10, \mathrm{H} 7$ and $\mathrm{H} 8$ are in agreement with those of the corresponding protons in the dihydropyridone synthesized by Sogiyama et al. [21], which appear at 2.75, 3.31, 5.2, 6.42 and 7.44 ppm respectively. 
Table 2. Chemical shifts $\left(\delta\right.$, ppm) of ${ }^{13} \mathrm{C}$ of the studied compounds.

\begin{tabular}{llllll}
\hline C & 1.0 & 3.0 & 6.0 & 7.0 & 8.0 \\
\hline C1 & 122.0 & 121.7 & 121.6 & 121.8 & 121.7 \\
C2 & 119.1 & 119.1 & 191.3 & 119.7 & 119.7 \\
C3 & 147.8 & 147.6 & 147.8 & 148.0 & 148.2 \\
C4 & 148.1 & 148.1 & 148.0 & 148.0 & 148.2 \\
C5 & 147.8 & 147.8 & 147.7 & 148.2 & 148.1 \\
C6 & 130.4 & 130.2 & 130.2 & 130.6 & 130.4 \\
C7 & 137.5 & 137.2 & 137.4 & 138.3 & 138.0 \\
C8 & 115.7 & 115.5 & 115.6 & 116.3 & 116.3 \\
C9 & 160.6 & 160.6 & 160.5 & 160.9 & 160.7 \\
C10 & 95.8 & 95.8 & 95.8 & 95.9 & 95.9 \\
C11 & 188.1 & 188.0 & 188.0 & 188.1 & 188.1 \\
C12 & 42.7 & 42.8 & 42.8 & 42.8 & 42.7 \\
C13 & 60.4 & 60.5 & 60.5 & 60.7 & 60.7 \\
C14 & 127.6 & 127.2 & 127.7 & 127.7 & 127.8 \\
C15 & 111.0 & 110.9 & 110.0 & 111.6 & 111.4 \\
C16 & 147.8 & 147.8 & 147.9 & 148.6 & 148.8 \\
C17 & 146.1 & 146.8 & 147.1 & 146.5 & 146.1 \\
C18 & 115.2 & 115.2 & 115.0 & 115.7 & 115.4 \\
C19 & 118.6 & 118.5 & 119.2 & 118.8 & 118.8 \\
C20 & 55.7 & 55.7 & 55.7 & 55.7 & 55.7 \\
C21 & 55.6 & 55.6 & 55.6 & 55.6 & 55.6 \\
C22 & 48.6 & 51.6 & 49.8 & 148.3 & 147.0 \\
C23 & ----- & 22.5 & 138.0 & 117.0 & 114.7 \\
C24 & ----- & 10.9 & 128.7 & 131.1 & 127.0 \\
C25 & ----- & ----- & 126.1 & 119.6 & 127.6 \\
C26 & ----- & ----- & 128.7 & 131.0 & 127.0 \\
\hline & & & & & \\
\hline
\end{tabular}

The chemical shifts of ${ }^{13} \mathrm{C}$ NMR spectra of some of the studied compounds are gathered in Table 2. The spectra are almost identical and characterized by signal at $188 \mathrm{ppm}$ which indicates the presence of the carbonyl group in these compounds. The carbon atom that attached to the vinylic proton $(\mathrm{H} 10)$ has a distinguished peak at $95 \mathrm{ppm}$ as indicated by the HETCOR spectrum (Figure 3). The chemical shifts of these two peaks are in agreement with those found in the dihydropyridones synthesized by Hermata and Lee, ${ }^{9}$ which were appeared at 190 and 96 ppm respectively. The peak at $160 \mathrm{ppm}$ has the same chemical shift for $=\mathrm{C}-\mathrm{N}$ carbons in cyclic enamines, ${ }^{26}$ accordingly it could be attributed to the carbon C9. On the basis of ${ }^{13} \mathrm{C}$ NMR spectra of curcumin, ${ }^{13,14}$ in which the aromatic carbons that attached to the OMe and $\mathrm{OH}$ groups have peaks at 150 and $148.8 \mathrm{ppm}$ respectively, the signals appear within the range $148-145 \mathrm{ppm}$ are assigned to the atoms $\mathrm{C} 3, \mathrm{C} 4, \mathrm{C} 16$ and $\mathrm{C} 17$. The olefinic and other aromatic carbons are 
characterized by peaks within the range $115-130 \mathrm{ppm}$ and assigned with aid of HETCOR spectra. In order to get more evidence about the origin of the signals at 2.40 and $2.84 \mathrm{ppm}$ an attempt was undertaken to reproduce the ${ }^{3} J$ coupling constants of these signals using Carplus equation, ${ }^{25}$ (equation 1 ).

$$
{ }^{3} J=7-\cos \varphi+5 \cos 2 \varphi
$$

Because of lack to crystallographic data for the studied compounds the molecular structure of compound 1 was calculated using the B3LYP/6-311G(d,p) level of theory (Figure 5). The calculated values for the dihedral angles H12-C12-C13-H13 and H12'-C12-C13-H13 for the optimized structure (Figure 5) were -64 and $175^{\circ}$ respectively. Substituting these values in equation 1 gave ${ }^{3} J$ values of 3.4 and $10.9 \mathrm{~Hz}$ respectively. The values are in coarse agreement with the experimentally measured values ( 4 and $7 \mathrm{~Hz}$ respectively). Accordingly it is fair to conclude that the signals that appear at 2.42 and $2.84 \mathrm{ppm}$ could be assigned to the protons H12' and $\mathrm{H} 12$ respectively. On the basis of this finding the cross peaks that appear in Figure 4 for the peaks 2.43 and $5.03 \mathrm{ppm}$ indicate a long range coupling between the proton H12' and the vinylic proton $\mathrm{H} 10$.

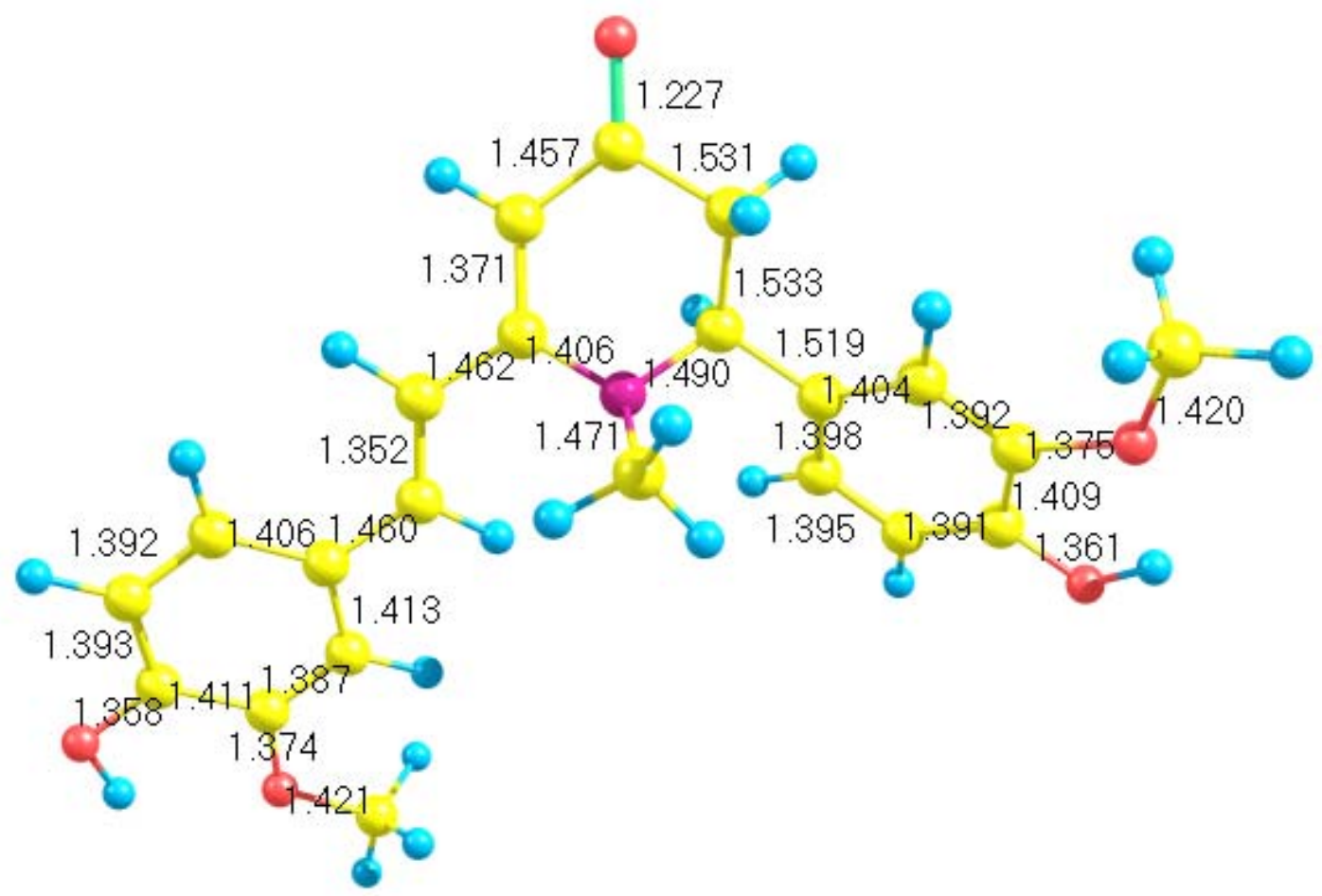

Figure 5. The optimized structure of compound 1 (B3LYP/6-311G(d,p)).

The optimized structure of compound 1 (Figure 5) was used to calculate ${ }^{1} \mathrm{H}$ and ${ }^{13} \mathrm{C}$ chemical shifts at the level B3LYP/6-311G(d,p)//B3LYP/6-311G(d,p) using the GIAO method. The theoretical values for ${ }^{1} \mathrm{H}$ and ${ }^{13} \mathrm{C}$ NMR of this compound are given in Table 3 . In order to 
compare the experimental and theoretical chemical shifts, the correlation graphics based on the calculations have been presented in Figure 6. The correlation values of the proton and carbon chemical shifts are found to be 0.9854 and 0.9923 respectively. The calculated chemical shift for the $\mathrm{OH}$ proton found to be $5.6 \mathrm{ppm}$ which underestimated compare to the experimental values. This may rationalized on the basis that experimental chemical shifts of this proton depends on many things such as the solvent used, the temperature, the concentration and the hydrogen bonding in solution, while the theoretical calculations are done for the gas phase. Accordingly the $\mathrm{OH}$ proton signal not included in Figure 6.

Table 3. Calculated ${ }^{1} \mathrm{H}$ and ${ }^{13} \mathrm{C}$ NMR chemical shifts (ppm) of compound 1 (GIAO, B3LYP/6$311 \mathrm{G}(\mathrm{d}, \mathrm{p}) / / \mathrm{B} 3 \mathrm{LYP} / 6-311 \mathrm{G}(\mathrm{d}, \mathrm{p})$.

\begin{tabular}{llll}
\hline Carbon & Chemical shift & Proton & Chemical shift \\
\hline C11 & 184.8 & H2 & 7.50 \\
C9 & 158.6 & H7 & 6.91 \\
C4 & 146.6 & H15 & 6.88 \\
C3 & 145.4 & H8 & 6.70 \\
C5 & 145.1 & H5 & 6.60 \\
C16 & 144.6 & H18 & 6.80 \\
C17 & 142.4 & H6 & 7.00 \\
C7 & 132.7 & H19 & 6.81 \\
C6 & 126.8 & OH & 5.50 \\
C14 & 126.3 & H13 & 4.67 \\
C1 & 123.4 & OCH & 3.90 \\
C2 & 114.3 & OCH & 3.70 \\
C19 & 119.2 & H12 & 2.78 \\
C8 & 115.2 & N-CH & 3.00 \\
C15 & 110.8 & H12 & 2.17 \\
C15 & 104.6 & -------- & -------- \\
C10 & 102.0 & -------- & ----- \\
C13 & 62.4 & ------- & ------ \\
C20 & 54.6 & -------- & ------ \\
C21 & 54.5 & --------- & ------ \\
C22 & 52.3 & -------- & -------- \\
C12 & 36.9 & -------- & ------ \\
\hline
\end{tabular}



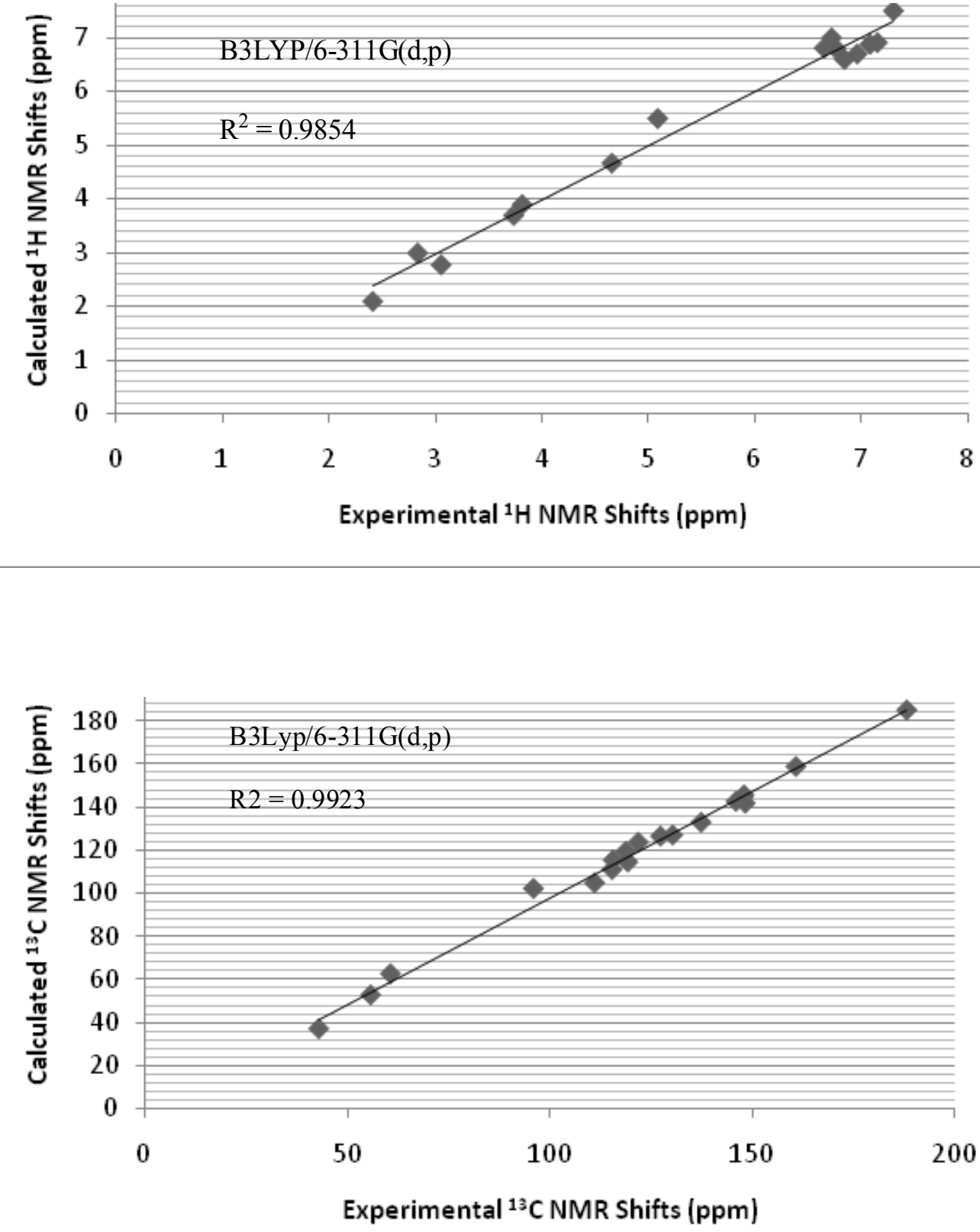

Figure 6. Plot of the calculated vs. the experimental ${ }^{1} \mathrm{H}$ NMR, and ${ }^{13} \mathrm{C}$ NMR chemical shifts (ppm). 


\section{References}

1. Ohts, H.; Xiao, Z.; Ishida, J.; Nagai, M.; Wang, H-K.; Itokawa, H.; Su, C-Y.; Shih, C.; Chiang, T.; Chang, E.; Li, Y.; Tsai, M-Y.; Chang ,C.; Lee, K-H.; J. Med. Chem. 2002, 45, 503.

2. Masuda, T.; Mackawa, T.; Hidaka, K.; Bando, H.; Takeda, Y.; Yamaguchi, H. J. Agric. Food Chem. 2001, 49, 2539.

3. Balasubramanian, K., J. Agric. Food Chem. 2006, 54, 3512.

4. Park, S. Y.; Kim, D. S. J. Nat. Prod. 2002, 56, 1227.

5. Asai, A.; Magasawa, T.; J. Nutr. 2001, 131, 2932.

6. Leu, T. H.; Maa, M. C. Med. Chem. Anti-Cancer. Agents 2002, 2, 357.

7. Shishodia, S.; Potdar, P.; Gairola, C. G.; Aggarwal, B. B. Carcenogenesis 2003, 24, 1269.

8. Lim, G. P.; Chu, T.; Yang, F.; Beech, W.; Frautschy, S. A.; Cole, C. M. J. Neurosci. 2001, 21,8370 .

9. Harmata, M.; Lee, D. R. Arkivoc 2007, (v), 91.

10. Comins, D. L. J. Heterocycl. Chem. 1999, 36, 1491.

11. Joseph, S.; Comins, D. L. Curr. Opin. Drug. Discov. Devel. 2002, 5, 870.

12. Harmata, M.; D. R. Lee. J. Am. Chem. Soc. 2002, 124, 14328.

13. Harmata, M.; Lee, D. R.; Barnes, C. L. Org. Lett. 2005, 7, 1881.

14. Etexebarria, J.; Vicario, J. L.; Badia, D.; Corrillo, L. J. Org. Chem. 2004, 69, 2588.

15. Tewari, N.; Katiyar, D.; Tiwari, V. K.; Tripathi, R. P. Tet. Lett. 2003, 44, 6639.

16. Guo, H.; Ding, K. Tet. Lett. 2003, 44, 7103.

17. Mancheno, O.; Arrayas, R. G.; Carretero, J. C. J. Am. Chem. Soc. 2004, 126, 456.

18. Comins, D. L.; Joseph, S. P.; Goehring, R. R. J. Am. Chem. Soc. 1994, 166, 4719.

19. Comins, D. L.; Goehring, R. R.; Joseph, S. P.; Connor, S. O. J. Org. Chem. 1990, 55, 2574.

20. Comins, D. L.; Joseph, S. P. Advances in Nitrogen Heterocycles JAI Press Inc, 1996; Vol.2, p. 183.

21. Sugiyama, N.; Yamamoto, M.; Kashima, Ch. Bull. Chem. Soc. Jpn. 1970, 43, 3937.

22. Gayaprakasha, G. K.; Rao, L. J. M.; Sakariah, K. K. J. Agric. Food Chem. 2002, 50, 3668.

23. Gaussian 2003. Gaussian, Inc. Carnegie Office Park, Building 6, Pittsburgh, PA 15106, USA.

24. Wolinski, K.; Himton, J. F.; Pulay, P. J. Am. Chem. Soc. 1990, 14, 8251.

25. Macomber, R. S. A Complet Introduction to Modern NMR Spectroscopy, Wiley: New York, 1998; p 216.

26. Saeed B. A.; Musad, I. M. Molecules 2009, 14, 2278. 